\title{
Bandwidth Enhancement of Corporate Fed Bowtie Antenna Array operating in L Band by Changing the Substrate Material and Ground Plane Length
}

\author{
Tapan Nahar \\ Research Scholar \\ Department of ECE \\ Poornima College of Engineering, Jaipur
}

\author{
O. P. Sharma \\ Professor \\ Department of ECE \\ Poornima College of Engineering, Jaipur
}

\begin{abstract}
This paper presents analysis of Multiband Corporate fed Bowtie Antenna Array having tuned in L Band. Bandwidth performance is analyzed for different substrate materials and effect of ground plane is presented. Simulation result shows that proposed antenna using Roggers RT/Duroid matarial is tuned at frequencies $1.05 \mathrm{GHz}, 1.63 \mathrm{GHz}, 2.25 \mathrm{GHz}$ and $2.92 \mathrm{GHz}$ and provides $40.95 \%, 18.40 \%, 14.66 \%$ and $17.97 \%$ bandwidth respectively. Proposed antenna can be used for applications such as WCDMA, Mobile Satellite services, point to point, TV pickup and subscriber radio system (SRS). The antenna is simulated on HFSS virtual tool.
\end{abstract}

\section{General Terms}

Antenna design \& analysis, RF design, Wireless communication, Microstrip antennas.

\section{Keywords}

Microstrip patch antenna, substrate material, Impedance Bandwidth, HFSS bowtie antenna, corporate feed Network.

\section{INTRODUCTION}

The Microstrip antennas are best suited where size, weight, cost, and ease of installation demand a low profile antenna [1]. It is widely used in high performance space crafts, aircrafts, satellite applications, wireless communication, radar and mobile communications. It is suitable for planner as well as non planer surfaces. It can be fabricated using printed circuit technology so it is simple and inexpensive. But there are several operational disadvantages of this antenna the bandwidth, efficiency, gain and power handling capacity of microstrip antenna is very low. Many scientists have done the research for increasing the bandwidth and gain. The gain of antenna can be increased by using the array configuration [2]. Microstrip patch antenna is made of metal patches placed on dielectric substrate and fed by microstrip or coplanar transmission line. The resonating frequency, radiation pattern, antenna impedance and polarization can be controlled by properly selecting the shape and dimension of patch [3]. Bandwidth of microstrip patch antenna can be increased by increasing the width and height of patch and decreasing the dielectric constant of substrate [4]. Losses are increased and efficiency is decreased because of increment in the volume [5]. Bandwidth is also dependent on impedance matching. There are several impedance matching techniques like quarter wave line [4-6], aperture coupled feeding technique [7] and slotted patches. Different shapes of slots like H shape [4], U shape [7], annular ring shape [8], L shape [9] and inverted F shape [10] are popular. Bandwidth can also be increased by stacking of patches [11].

In this paper, two triangular slots are cut in the rectangular shaped patch to make a bowtie shaped structure [12]. Array of four patches are fed by corporate fed network. The proposed antenna is simulated on HFSS virtual tool. The corporate fed networks and triangular slots are used for increasing the bandwidth and array is used for increasing the gain.

This Paper is divided into five sections. Section I describes the introduction. Antenna geometry is presented in section II. Section III consist the simulation results of bow tie shaped antenna array. Performance analysis of proposed antenna by changing the ground plane length and substrate material is discussed in Section IV. Paper is concluded in section V.

\section{ANTENNA GEOMETRY}

Proposed antenna is designed on the FR4 substrate of $400 * 200 * 1.6$ cube $\mathrm{mm}$ having relative permittivity 4.4 . Each triangular shaped patches are separated by distance of 62.5 $\mathrm{mm}$ far apart from each other and fed by Corporate type feed network (symmetrical fed network) as shown in Fig 1 . Triangular patch having $62.5 \mathrm{~mm}$ base and $27.9 \mathrm{~mm}$ height. Two triangles are arranged in bow-tie shaped as shown in figure 1.

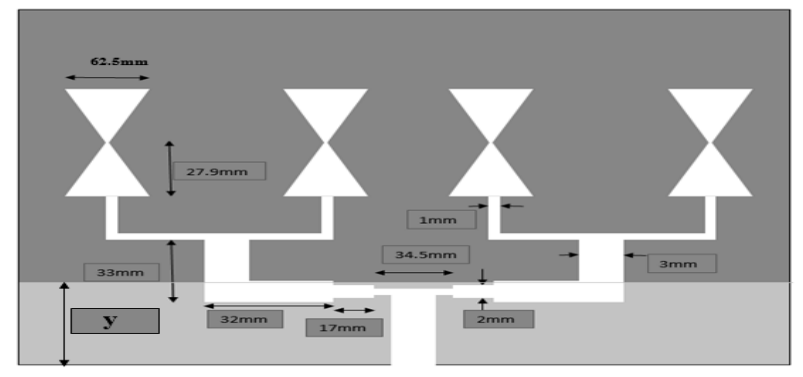

Fig 1: Geometry of Bowtie Shaped Antenna Array

All elements are connected to central feed port via equal length to provide uniform phase distribution. Due to symmetrical properties of network, each individual element is separated by distance of $\lambda / 2$ from each other in linear way along $y$-axis. Spacing of $\lambda / 2$ is chosen to reduce combat fading. Due to this spacing, the signals received from different antenna elements are independent in uniform scattering environment. It should be less or equal to $\lambda / 2$ (the nyquist rate) to avoid aliasing [13-14]. The partial ground plane of length $\mathrm{y}$ is used.

\section{SIMULATION RESULTS}

Proposed antenna is simulated on HFSS virtual tool. The simulated return loss versus frequency plot is shown in Fig 2 . It presents the reflections of antenna towards source due to mismatching of impedances with respect to frequency. It is observed that antenna resonates at $1.17 \mathrm{GHz}, 1.65 \mathrm{GHz}, 2.12$ $\mathrm{GHz}$ and $2.5 \mathrm{GHz}$ frequencies and providing bandwidth $16.23 \%, 12.9 \%, 8.47 \%$ and $7.2 \%$ respectively. 


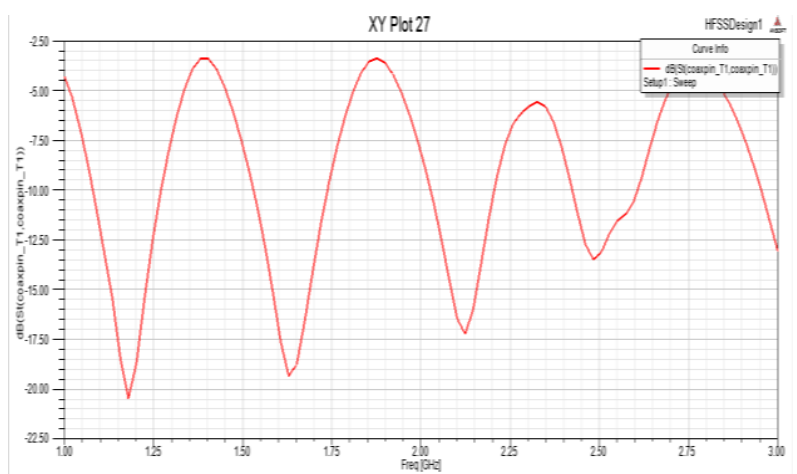

Fig 2: Return loss versus frequency plot.

The radiation pattern in 2D is shown in Fig 3. The radiation is obtained between -90 degree to +90 degree which represents that it is above the ground plane.
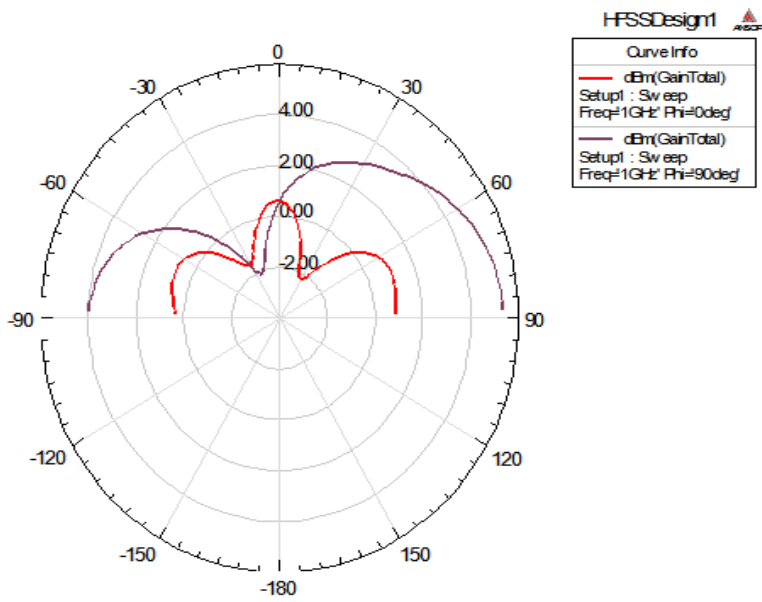

Fig 3: Radiation pattern in 2D.

The radiation pattern in $3 \mathrm{D}$ is presented in Fig 4.
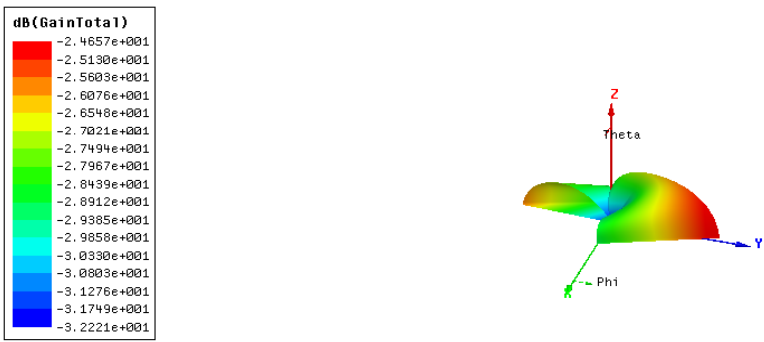

Fig 4: Radiation pattern in 3D.

Simulated VSWR of proposed antenna v/s frequency plot is presented in Fig 5.

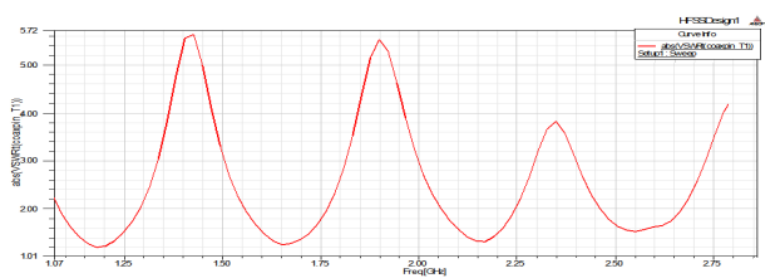

Fig 5: VSWR v/s frequency plot.
It may be observed that VSWR of proposed antenna is minimum at four frequencies $1.17 \mathrm{GHz}, 1.65 \mathrm{GHz}, 2.12 \mathrm{GHz}$ and $2.50 \mathrm{GHz}$.

The axial ratio variation with frequency of simulated proposed antenna is shown in Fig 6.

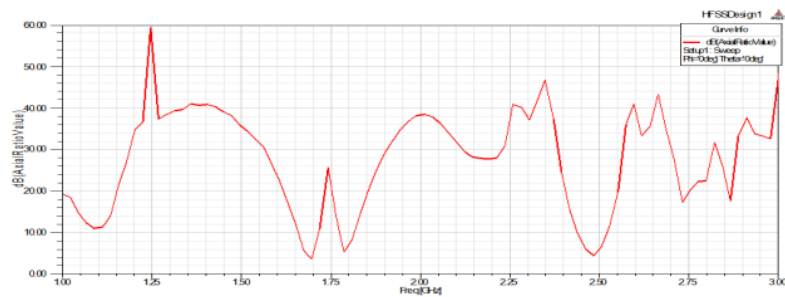

Fig 6: axial ratio v/s frequency plot.

From the axial ratio v/s frequency plot, it may be observed that value of axial ratio for proposed arrangement is greater than desired $3 \mathrm{~dB}$ value means it is linearly polarized.

Smith chart represents the variation of simulated input impedance of proposed arrangement as a function of frequency which is shown in Fig 7.
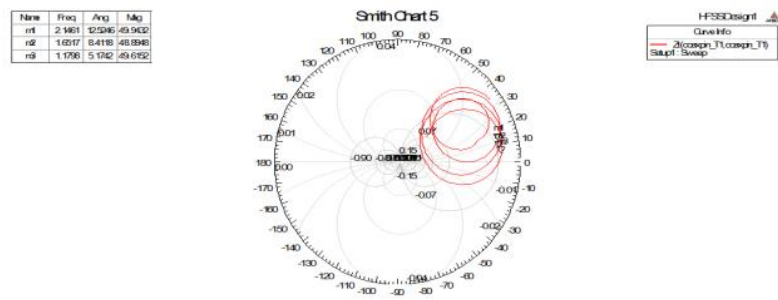

Fig 7: Smith Chart of proposed antenna

The input impedance of this proposed arrangement at resonance frequency $1.1798 \mathrm{GHz} 1.65 \mathrm{GHz}$ and $2.14 \mathrm{GHz}$ is $49.6152|5.1742, \quad 48.8948| 8.4118$ and $49.9432 \mid 12.5246$ which again suggests excellent matching between feed arrangement and antenna at resonant frequency.

Gain of proposed antenna using HFSS is presented in Fig 8. Gain value at resonant frequency $2.12 \mathrm{GHz}$ is $18 \mathrm{dBm}$.

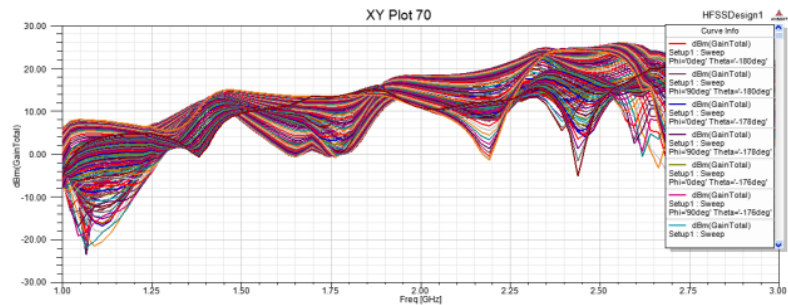

Fig 8: Gain v/s frequency plot

\section{PERFORMANCE ANALYSIS OF BOWTIE ANTENNA ARRAY}

It is observed from the simulation results that antenna has small bandwidth of $16.23 \%$ at $1.17 \mathrm{GHz}$ frequency. For further enhancement of bandwidth, two strategies are adopted.

\subsection{Variation in Ground Plane Length}

It is observed that bandwidth of antenna is improved by changing the length of ground plane and there is very less variation in bandwidth when the width of ground plane is varied represented in Fig 9 and Table 1. 
Table 1. Effect of ground plane length

\begin{tabular}{|c|c|c|c|c|}
\hline S. & Ground & \multicolumn{3}{|c|}{ \% Bandwidth } \\
plane \\
\cline { 3 - 5 } No. & $\begin{array}{c}\text { length(y) } \\
\text { in } \mathbf{~ m m}\end{array}$ & $\mathbf{F r = 1 . 1 7}$ & $\mathbf{F r}=\mathbf{1 . 6 5}$ & $\mathbf{F r}=\mathbf{2 . 1 2}$ \\
& & $\mathbf{G H z}$ & $\mathbf{G H z}$ & $\mathbf{G H z}$ \\
\hline 1 & 20 & 16.23 & 12.72 & 8.37 \\
\hline 2 & 50 & 17.09 & 12.12 & 8.83 \\
\hline 3 & 100 & 15.38 & 12.05 & 8.37 \\
\hline 4 & 150 & 16.23 & 12.12 & 8.37 \\
\hline
\end{tabular}

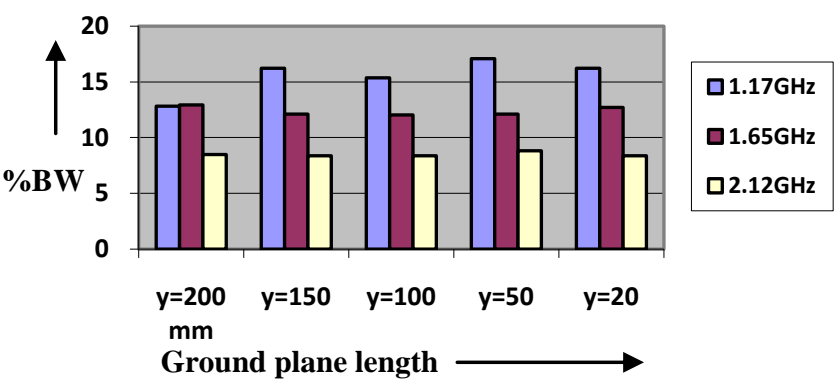

Fig 9: Bandwidth versus ground plane length plot.

As the length y of ground plane is decreased the bandwidth is increased. Optimum ground plane length is $50 \mathrm{~mm}$ where bandwidth is $17.09 \%$ at $1.17 \mathrm{GHz}$ and $8.83 \%$ at $2.12 \mathrm{GHz}$ frequency.

\subsection{Variation in Substrate Materials}

As refractive index of substrate material is decreased, the bandwidth of antenna is increased but losses are also increased. Three materials are used: FR4 $(\varepsilon r=4.4)$, Epoxy Kevlar $(\varepsilon r=3.6)$ and Roggers RT/Duroid ( $\mathrm{r} r=2.2)$. Comparative analysis of bandwidth is represented in Fig 10 and Table 2.

Table 2. Effect of substrate material on bandwidth

\begin{tabular}{|c|c|c|c|c|c|}
\hline S. & Substrate & \multicolumn{4}{|c|}{$\%$ Bandwidth } \\
\cline { 3 - 6 } No. & Material & $\begin{array}{c}\text { First } \\
\text { resonant } \\
\text { frequency }\end{array}$ & $\begin{array}{c}\text { Second } \\
\text { resonant } \\
\text { frequency }\end{array}$ & $\begin{array}{c}\text { Third } \\
\text { resonant } \\
\text { frequency }\end{array}$ & $\begin{array}{c}\text { Forth } \\
\text { resonant } \\
\text { frequency }\end{array}$ \\
\hline 1 & FR4 & 17.09 & 12.12 & 8.83 & -- \\
\hline 2 & $\begin{array}{c}\text { Epoxy } \\
\text { Kevlar }\end{array}$ & 17.82 & 12.707 & 12.765 & 8.77 \\
\hline 3 & $\begin{array}{c}\text { Roggers } \\
\text { RT/Duroid }\end{array}$ & 40.95 & 18.4 & 14.66 & 17.97 \\
\hline
\end{tabular}

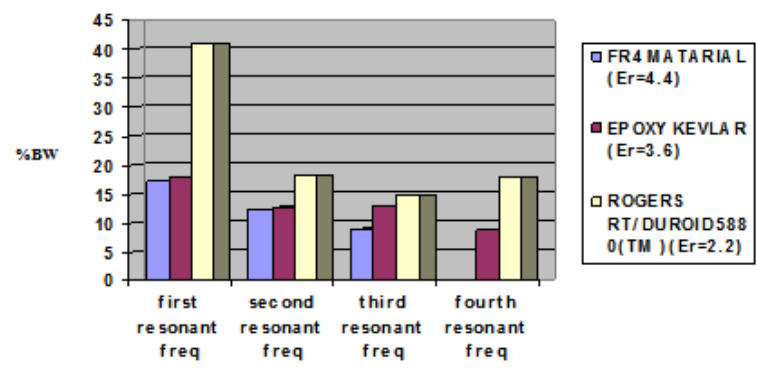

Fig 10: Bandwidth plot for different substrate material
It may be observed from Fig 10 that there is significant enhancement in bandwidth for substrate of low dielectric constant. Maximum bandwidth is achieved by using RT/Duroid substrate but losses are also increased but if these losses are under permissible limit for some applications than it is good option.

The effect of refractive index on return loss is represented in Fig 11 and Table 3.

Table 3. Effect of substrate material on return loss

\begin{tabular}{|c|c|c|c|c|c|}
\hline S. & Substrate & \multicolumn{4}{|c|}{ Return loss in dB } \\
\cline { 3 - 6 } No & Material & $\begin{array}{c}\text { First } \\
\text { resonant } \\
\text { freq. }\end{array}$ & $\begin{array}{c}\text { Second } \\
\text { resonant } \\
\text { freq. }\end{array}$ & $\begin{array}{c}\text { Third } \\
\text { resonant } \\
\text { freq. }\end{array}$ & $\begin{array}{c}\text { Forth } \\
\text { resonant } \\
\text { freq. }\end{array}$ \\
\hline 1 & FR4 & -21 & -19 & -17 & -13.5 \\
\hline 2 & $\begin{array}{c}\text { Epoxy } \\
\text { Kevlar }\end{array}$ & -40 & -30 & -24.5 & -15.5 \\
\hline 3 & $\begin{array}{c}\text { Roggers } \\
\text { RT/Duroid }\end{array}$ & -25 & -24 & -41 & -29 \\
\hline
\end{tabular}

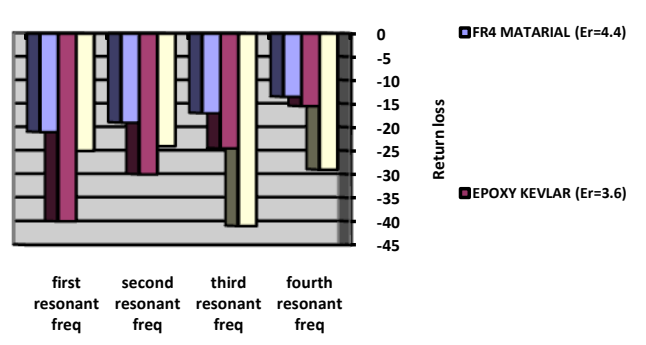

QROGERS RT/DUROID5880(TM)(Er=2.2)

Fig 11: Return loss for different materials It may be observed from the Fig 11 and Table 3 that return loss is increased at first and second resonant frequencies for Roggers RT/Duroid substrate which has lowest dielectric constant in above mentioned geometries. The wide bandwidth factor can be utilized if losses are accepetable for any specific application.

\section{CONCLUSION}

In this paper, the performance of Bow tie antenna array is analyzed. Bandwidth is increased due to decreasing the ground plane length and almost constant due to changing the ground plane width. As the refractive index is decreased the bandwidth of proposed antenna is increased. For Rogers RT/Duroid material , the same geometry provides $40.95 \%$, $18.40 \%, 14.66 \%, 17.97 \%$ and $8.85 \%$ at $1.05 \mathrm{GHz}, 1.63 \mathrm{GHz}$, $2.25 \mathrm{GHz}, 2.92 \mathrm{GHz}$ and $3.5 \mathrm{GHz}$ respectively which can be used for WCDMA, Mobile Satellite services, point to point, TV pickup and subscriber radio system (SRS). Stacked arrangement of patches and modified ground plane structure can be used for achieving more enhancements in bandwidth. Gain can be further enhanced by increasing the no. of elements in array configuration. 


\section{REFERENCES}

[1] Jhaman das, Tzeem Ahmad Khan and Manoj kumar pal 2012, "Rectangular patch antenna array for wireless applications", IJEST, Vol.4, No.10.

[2] John D Kraus, Ronald J Marhefka and Ahmad S Khan 2007, “Antenna \& Wave Propagation", Fourth edition, TMH India.

[3] D.M. Pozar 1992, "Microstrip Antennas", Proc. IEEE, Vol.80, No.1, pp. 79-81.

[4] Sudhir Bhaskar and Sachin Kumar Gupta 2012,"Bandwidth Improvement of Microstrip Patch Antenna using H-Shaped Patch", IJERA, Vol.2, Issue 1.

[5] J.R. James and P.S. Hall 1989, "Handbook of Microstrip Antennas", Peter Peregrinus Ltd., on behalf of the IEEE, Vol. 1.

[6] I.J. Bahl and P. Bhartia 1980, "Microstrip Antennas", Artech House, Norwood.

[7] Aruna Rani and R.K. Dawre 2010 , "Design and Analysis of Rectangular and U slotted microstrip patch using Optimization Program in Java for UHF Application", IJCA, Vol. 5, No.5.
[8] S. Azzaz-Rahmani and N. Boukli-Hacene 2012, "UltraWide-Band Microstrip concentric annular ring antenna for wireless communications", IJCSI, Vol.9, Issue1, No2.

[9] Kin-Lu Wong 2002, "Compact and Broadband Microstrip Antennas", John Wiley \& Sons.

[10] K. L.Wong and K. P. Yang 1998, "Modified planar inverted F antenna", Electron. Lett. 34, No. 6-7.

[11] A.G. Derneryd 1979, "Extended analysis of rectangular microstrip resonator antennas", IEEE Trans. Antennas Propagat., Vol. AP-27, No.6, pp.846-849.

[12] Tapan Nahar and Om Prakash Sharma 2014, “A Modified Approach for Bandwidth Enhancement of Microstrip Patch Antenna in L Band", First Edition, NSAWOA-2014 Proceedings.

[13] D.M.Pozar 1986, "Finite phased arrays of rectangular microstrip antennas", IEEE Trans. Antennas Propagat., Vol.AP-34, No.5, pp.658-665.

[14] D.H. Johnson and D.E. Dudgeon 1993, "Array Signal Processing: Concepts and Techniques", Prentice Hall PTR, Englewood Cliffs, NJ. 